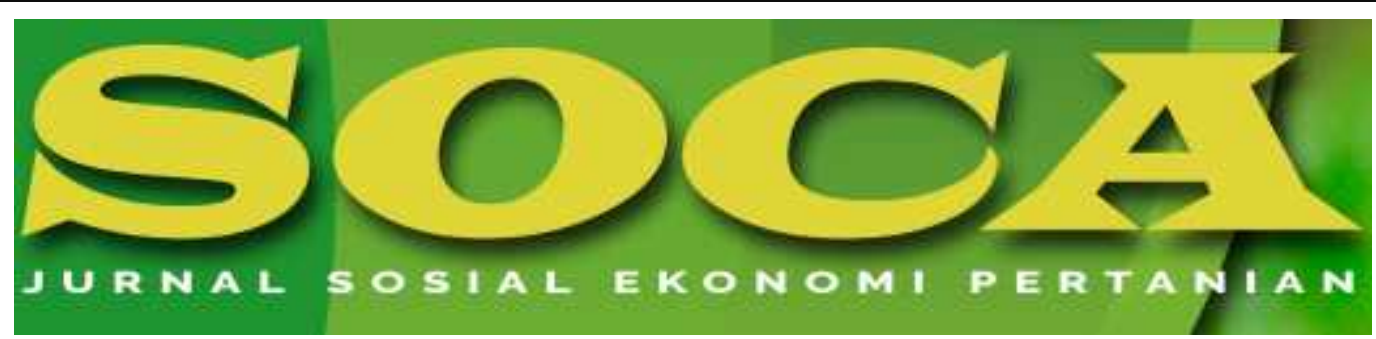

https://ojs.unud.ac.id/index.php/soca

\title{
ANALISIS NILAI TUKAR PETANI BUNGA KRISAN PADA ANGGOTA KELOMPOK TANI GEMAH RIPAH DI DUSUN CLAPAR DESA DUREN KECAMATAN BANDUNGAN KABUPATEN SEMARANG
}

\begin{tabular}{l} 
Kata $\quad$ Kunci: \\
bunga \\
nilaisan, \\
petani, \\
pendapatan \\
\hline
\end{tabular}

Kata Kunci: bunga krisan, nilai pendapatan

\author{
Lana Khusnia Shifa, Kustopo Budiraharjo dan Wiludjeng Roessali \\ Program Studi Agribisnis Fakultas Peternakan dan Pertanian \\ Universitas Diponegoro, Kampus Tembalang - Semarang 50275 \\ Email:1anakhusnia17@gmail.com,kustopo.65@gmail.com,danwroessali@gmail.com, \\ Telepon/Hp: 085865856800, 081225738308, 08122862835
}




\section{ANALYSIS OF EXCHANGE RATE OF CRISAN FARMERS IN GEMAH RIPAH FARMERS GROUP IN CLAPAR DUREN VILLAGE, DUREN DISTRICT, BANDUNGAN, SEMARANG DISTRICT}

Keywords:
chrysanthemum
flowers, farmer
exchange rates,
income

Keywords:

chrysanthemum flowers, farmer income

\begin{abstract}
Abstrak
Chrysanthemum flowers are a commodity that has the potential to be used as a source of income. Problems that often in chrysanthemum farming are the relatively small scale of farming, unstable price fluctuations and lack of knowledge of farmers on the calculation of production costs and income. Farmer welfare can be measured by farmer exchange rate. This study aims to analyze the NTP in 2017 with 2018 and to analyze the factors that influence the NTP of chrysanthemum flowers. This research was conducted in october 2018 at the gemah ripah farmer group. The research method used is the census method. The number of respondents is 30 people who are members of the gemah ripah farmer group. The method of analisys uses quantitative methods by calculating chrysanthemum NTP, paired sample T-test and multiple linier regression test. The results of the analysis show that NTP in 2017 is 175\% up to $179 \%$ in 2018, this means that farmers are in a prosperous condition. The paired sample T-test results showed a significant difference between NTP in 2017 and 2018 with a significance value of $0,017<0,05$. Variable area of land, production costs, receipt of chrysanthemum farming, household expenses and family members significantly influence the NTP of chrysanthemum.
\end{abstract}

How to Cite (APA 6th Style):

Shifa, L. K., Budiraharjo, K., \& Roessali, W. (2019). Analisis Nilai Tukar Petani Bunga Krisan Pada Anggota Kelompok Tani Gemah Ripah di Dusun Clapar Desa Duren Kecamatan Bandungan Kabupaten Semarang. SOCA: Jurnal Sosial Ekonomi Pertanian, 13(3), 355-365. https://doi.org/https://doi.org/10.24843/SOCA.2019.v13.i03.p06

\section{PENDAHULUAN}

Bunga krisan merupakan bunga hias yang mempunyai banyak warna tahan lama dan harganya yang murah. Menurut Sarwono (1992) bunga krisan merupakan salah satu bunga potong yang sangat popular dikalangan masyarakat luas, bunga krisan merupakan bunga potong yang mempunyai nilai komersil yang tinggi di Indonesia. Salah satu sentra produksi bunga krisan terbesar di di Kabupaten semarang yaitu di Kecamatan Bandungan tepatnya di Dusun Clapar Desa Duren Kecamatan Bandungan Kabupaten semarang merupakan salah satu daerah yang cocok digunakan untuk usahatani bunga krisan.

Tingginya permintaan bunga krisan di kalangan masyarakat menjadi peluang tersendiri bagi petani krisan di daerah tersebut terlebih bunga krisan dapat dipanen sesuai permintaan konsumen. Yang mana hal tersebut dapat meningkatkan 
pendapatan petani dan kesejahteraan petani. Permasalahan yang sering terjadi bagi usahatani bunga krisan adalah usahatani dilakukan oleh petani dengan skala kecil, tidak ada patokan harga dari pemerintah sehingga harga ditingkat petani tidak stabil dan kurangnya pengetahuan petani bunga krisan dalam perhitungan biaya produksi dan pendapatan. Karena itu diperlukan analisis lebih lanjut mengenai perhitungan pendapatan petani krisan dan NTP krisan sebagai pengukuran tingkat kesejahteraan petani.

Seiring berjalannya waktu bunga krisan di Kecamatan Bandungan semakin meningkat dan terkenal dengan dibukanya wisata bunga krisan di Dusun Clapar Desa Duren pada tahun 2016. Hal ini berimbas pada naiknya produktivitas bunga krisan di Kecamatan bandungan. Badan pusat Statistik (2016) menyatakan bahwa Kecamatan Bandungan menduduki posisi pertama dalam hal produktvitas bunga krisan di Kabupaten Semarang. Rata - rata pendapatan petani bunga krisan di Dusun Clapar Desa Duren Kecamatan Bandungan adalah Rp 34.429.472,- pertahun pada lahan seluas $1163 \mathrm{~m} 2$. Sehingga dapat disimpulkan bahwa peningkatan luas lahan bunga krisan mengakibatkan pendapatan petani bunga krisan juga semakin meningkat. Menurut Dinas Pertanian Kabupaten Semarang (2017) Kecamatan Bandungan tercatat memiliki luas panen bunga krisan terluas diantara kecamatan lain di kabupaten semarang seperti Ambarawa dan Sumowono. Luas lahan di kecamatan bandungan yaitu $1.608 .100 \mathrm{~m} 2$ dengan produksi bunga krisan sebanyak 102.515.870 tangkai.

Pertumbuhan ekonomi terumata dibidang pertanian secara umum belum tentu sejalan dengan kesejahteraan petani, misalnya dalam hal peningkatan pendapatan petani dan kemudahan akses sarana produksi pertanian. oleh sebab itu, penelitian ini dilaksanakan untuk mengetahui tingkat kesejahteraan petani bunga krisan di Dusun Clapar Desa Duren Kecamatan Bandungan. Kesejahteraan petani dapat diukur dengan rumus nilai tukar petani (NTP). NTP dapat diperoleh dengan cara membandingkan penerimaan petani dengan pengeluaran petani dan dinyatakan dalam presentase. Menurut Masyuri (2007) semakin tinggi NTP makan kesejahteraan petani juga akan kian meningkat.

Penelitian mengenai nilai tukar petani menarik untu dibahas karna sebelumnya belum terdapat penelitian dengan judul dan lokasi yang serupa. Perbedaan enelitian ini dengan penelitian lainnya yaitu terdapat bahasan yang menjelaskan faktor - faktor yang mempengaruhi NTP bunga krisan. Tujuan dari penelitian ini adalah untuk menganilisis nilai tukar petani pada tahun 2017 dengan nilai tukar petani pada tahun 2018 dan untuk menganilisi faktor - faktor apasajakah yang dapat memepengaruhi nilai tukar petani bunga krisan di Dusun Clapar Desa Duren Kecamatan Bandungan Kabupaten semarang.

\section{METODE PENELITIAN}

Peneltian ini dilaksakan pada bulan Oktober 2018 pada anggota kelompok Tani Gemah Ripah di Dususn Clapar Desa duren Kecamatan Bandungan Kabupaten Semarang. Metode penelitian yang dipakai dalam penelitian ini adalah sensus. Sensus merupakan sample jenuh yang mengambil seluruh populasi untuk dijadikan responden. Jumlah responden adalah 31 orang yang tergabunga dalam Kelompok tani Gemah Ripah. Jenis data yang dibutuhkan adalah data primer meliputi identitas responden dan harga jual bunga krisan dan data sekunder yang meliputi data geografis dan produksi pertanian. Metode pengukuran nilai tukar petani bunga krisan mengacu pada Arifin et., al (2012) : 


$$
\mathrm{NTP}=\mathrm{Yt} / \mathrm{Et}
$$

Keterangan:

NTP : Nilai Tukar Petani Bunga Krisan (\%)

Yt : Penerimaan usahatani bunga krisan (Rupiah)

Et : Total pengeluaran rumah tangga petani (Rupiah)

Indikator daya beli petani bunga krisan adalah sebagai berikut: jika NTP > $100 \%$, maka daya beli petani bunga krisan baik tetapi apabila $<100 \%$ daya beli petani belum baik (Sugiarto, 2008).

Metode analisis data yang digunakan adalah uji paired sample T-test dan uji regresi linier berganda.

Menurut sugiyono (2016) persamaan regresi linier berganda adalah sebagai berikut:

$$
\mathrm{Y}=\mathrm{a}+\mathrm{b} 1 \mathrm{X} 1+\mathrm{b} 2 \mathrm{X} 2+\mathrm{b} 3 \mathrm{X} 3+\mathrm{b} 4 \mathrm{X} 4+\mathrm{b} 5 \mathrm{X} 5+\mathrm{e}
$$

Keterangan:

$\mathrm{Y} \quad$ : NTP bunga krisan (\%)

$\mathrm{X} 1$ : Luas lahan $(\mathrm{m} 2)$

X2 : Biaya produksi (Rupiah/tahun)

X3 : Penerimaan bunga krisan (Rupiah/tahun)

X4 : Pengeluaran rumah tangga petani (Rupiah/tahun)

X5 : jumlah anggota keluarga (Orang)

Ee : error

\section{HASIL DAN PEMBAHASAN}

\section{Keadaan umum Kelompok Tani Gemah Ripah}

Kelompok Tani Gemah Ripah terletak di Dusun Clapar Desa Duren Kecamatan Bandungan Kabupaten semarang. Kelompok ini dibentuk tanggal 4 juni tahun 1996 pada awalnya kelompok ini beranggotakan 45 orang. Kelompo Tani Gemah ripah dikukuhkan oleh Dinas pertanian, perkebunan dan perhutanan Kabupaten semarang pada tanggal 22 desember 2008 dengan nomor 521/383/P/08 dan telah berbadan hokum dengan keputusan MENHUMKAM No. AHU0021002.AH.01.07 tahun 2015. Dusun Clapar Desa duren berada pada ketinggian lebih dari $700 \mathrm{mdpl}$, dengan suhu udara berkisar antara $20-27^{\circ} \mathrm{C}$. Luas lahannya adalah 10,0927 Ha. Petani di Dusun Clapar yang membudidayan bunga krisan sesuai dengan anjuran pemerintah baik dalam segi penggunaan benih, pupuk, pestisida dan penggunaan air maupun cara penerapannya.

\section{Karakteristik Resonden}

Responden pada penelitian ini yaitu 31 orang yang tergabung dalam Kelompok Tani Gemah Ripah dan menanam bunga krisan. Karakteristik responden antara lain luas lahan, pendidikan petani, umur responden dan jumlah anggota keluarga.

Tabel 1. Jumlah Responden Berdasarkan Umur

\begin{tabular}{lll}
\hline \hline Uraian & Jumlah & Presentasi \\
\hline & --- jiwa & $---\%_{----}^{--}$ \\
$\begin{array}{l}\text { Rata - rata luas lahan (m2) } \\
350-700\end{array}$ & 17 & 54,84
\end{tabular}




$\begin{array}{lll}701-1050 & 4 & 12,90 \\ 1.050-1.750 & 5 & 16,13 \\ \geq 1.751 & 5 & 16,13 \\ \text { Pendidikan petani } & \\ \text { SD } & 20 & 64,52 \\ \text { SMP } & 6 & 19,35 \\ \text { MA } & 5 & 19,15 \\ \text { Umur responden (Tahun) } & & \\ <30 & 3 & 9,68 \\ 30-39 & 10 & 32,26 \\ 40-49 & 9 & 29,03 \\ 50-59 & 4 & 12,90 \\ >59 & 5 & 16,13 \\ \text { Jumlah anggota keluarga (Orang) } & & \\ \leq 2 & 4 & 12,90 \\ 3-4 & 20 & 64,52 \\ \geq 5 & 7 & 22,58\end{array}$

Sumber: Diolah data primer, 2019

Berdasarkan tabel 1. Diketahui bahwa rata-rata luas lahan yang dimiliki oleh responden bervariasi yaitu berkisar antara $350 \mathrm{~m} 2$ hingga lebih dari $1.751 \mathrm{~m} 2$. Jumlah luas lahan terbanyak yaitu pada kisaran 350 - $700 \mathrm{~m} 2$, dengan jumlah responden 17 orang dan presentase sebesar 54,84\%, kemudian diikuti luas lahan $1.050-1.751 \mathrm{~m} 2$ dengan jumlah 5 orang dan presentase sebesar $16,13 \mathrm{~m} 2$. Terakhir luas lahan 701 - $1050 \mathrm{~m} 2$ dengan jumlah 4 orang dan presentase sebesar $12,90 \%$. Pendidikan responden paling banyak yaitu lulusan SD sejumlah 20 orang dengan presentase 64,52\%. Pendidikan responden kebanyakan SD karena keterbatasan rumah tangga petani dalam mengakses pendidikan sebelum berusahatani krisan. Petani di pedesaan mempunyai berbagai keterbatasan yaitu keterbatasan kemampuan, kurangnya modal usaha dan kurangnya informasi yang diakibatkan oleh berbagai faktor salah satunya pendidikan (Sartika, et., al 2016).

Karakteristik responden berdasarkan rentang umur responden paling banyak berjumlah 10 orang dengan renytang 30 - 39 tahun dengan presentase sebesar $32,26 \%$, kemudian diikuti oleh rentang umur 40 - 49 tahun dengan jumlah 9 orang dan presentase sebesar 29,03\%. Jumlah anggota keluarga paling banyak terdapat pada rentang $3-4$ tahun dengan jumlah 20 orang dan presentase sebesar $64,52 \%$, kemudian diikuti lebih dari 5 orang dengan presentase 22,58\%.

\section{Biaya Produksi Usahatani Bunga Krisan}

Berdasarkan Tabel 2. Diketahui bahwa biaya produksi bunga krisan di Dusun Clapar Desa Duren terdiri dari biaya tetap dan biaya variabel. Total dari biaya tetap tahun 2017 dan tahun 2018 yaitu Rp 401.675,- m2/tahun. Sewa lahan pada biaya tetap dibayarkan tiap tahun sekali akan tetapi dengan jumlah yang sama untuk 3 tahun terakhir, sedangkan penyusutan memiliki nilai yang sama karena tidak dipengaruhi oleh biaya produksi. Biaya variabel pada tahun 2017 yaitu Rp 1.651.403,- $\mathrm{m} 2$ /tahun meningkat menjadi $\mathrm{Rp} 1.797 .879,-\mathrm{m} 2 /$ tahun pada tahun 2018. Biaya variabel merupakan suatu biaya yang dikeluarkan petani dan 
jumlahnya berubah-ubah sesuai dengan kebutuhan untuk mencukupi input produksi.

Tabel 2. Biaya produksi bunga krisan

\begin{tabular}{lll}
\hline \multirow{2}{*}{ Komponen biaya } & \multicolumn{2}{c}{ Jumlah biaya produksi } \\
\cline { 2 - 3 } & \multicolumn{1}{c}{2017} & \multicolumn{1}{c}{ 2018 } \\
Biaya tetap (FC) & ------ rupiah/m2/tahun ---------- \\
Penyusustan & 392.250 & 392.250 \\
PBB & 1.273 & 1.273 \\
Sewa lahan & 8.152 & 8.152 \\
Total FC & 401.675 & 401.675 \\
Biaya variabel (VC) & & \\
Bibit & 502.200 & 558.000 \\
Pestisida & 178.488 & 189.170 \\
Pupuk & 76.611 & 84.929 \\
Listrik & 34.361 & 37.129 \\
Koran & 54.854 & 58.286 \\
Isolasi & 2.777 & 2.777 \\
Transport & 2.479 & 2.514 \\
Perawatan greenhouse & 6.914 & 8.226 \\
Pengairan & 1.319 & 1.319 \\
Tenaga kerja & 430.370 & 453.853 \\
Total VC & 1.249 .724 & 1.396 .204 \\
\hline Total biaya produksi (TC) & 1.651 .403 & 1.797 .879 \\
\hline Sumber: Diolah data primer, & &
\end{tabular}

Sumber: Diolah data primer, 2019

Berdasarkan Tabel 3. Diketahui total biaya produksi bunga krisan yaitu Rp 1.797.879,- m2/tahun. Menurut penelitian Utami (2013) diketahui bahwa total biaya produksi bunga anggrek yaitu Rp 1.460.000,- $\mathrm{m} 2 /$ tahun. Menurut penelitian Andri et., al (2015) diketahui bahwa total biaya produksi bunga mawar yaitu Rp. 1.282.497,- $\mathrm{m} 2 /$ tahun. Sehingga dapat disimpulkan bahwa biaya produksi paling tinggi terjadi pada bunga krisan.

Tabel 3. Perbedaan biaya produksi bunga krisan, anggrek dan mawar.

\begin{tabular}{lrrr}
\hline \multirow{2}{*}{ Total biaya } & \multicolumn{3}{c}{ Rata - rata biaya produksi } \\
\cline { 2 - 4 } & \multicolumn{1}{c}{ Krisan } & Anggrek & \multicolumn{1}{c}{ Mawar } \\
\hline & ------ Rp/ tahun ------- & & --- Rp/3bulan ---- \\
Biaya tetap & 401.675 & 1.260 .000 & 132.497 \\
Biaya variabel & 1.196 .204 & 200.000 & 1.150 .000 \\
Total biaya & 1.797 .879 & 1.460 .000 & 1.282 .497 \\
\hline
\end{tabular}

Sumber: Diolah data primer, 2019

\section{Penerimaan dan Pendapatan Usahatani Bunga Krisan}

Berdasarkan tabel 4. Diketahui total penerimaan bunga krisan pada tahun 2017 yaitu Rp 4.364.049,- $\mathrm{m} 2$ /tahun meningkat menjadi 4.482.274,- $\mathrm{m} 2$ /tahun. Penerimaan bunga krisan diperoleh dari penjualan hasil produksi dikali dengan 
harga bunga pertangkai. Suratiyah (2015) menyatakan bahwa penerimaan merupakan pendapatan dari usahatani sebelum dikurangi oleh biaya produksi. Pendapatan diperoleh dari selisih antara penerimaan bunga krisan dengan biaya produksi bunga krisan. Hasil dari pendapatan bunga krisan pada tahun 2017 sebesar Rp 2.454.228,- m2/tahun sedangkan pada tahun 2018 meningkat menjadi Rp 2.684.029,- m2/tahun.

Tabel 4. Penerimaan dan Pendapatan Usahatani bunga krisan

\begin{tabular}{|c|c|c|}
\hline \multirow{2}{*}{ Keterangan } & \multicolumn{2}{|c|}{ Penerimaan dan pendapatan } \\
\hline & 2017 & 2018 \\
\hline & \multicolumn{2}{|c|}{--------- Rp/m2/tahun -------- } \\
\hline Biaya tetap & 401.675 & 401.675 \\
\hline Biaya variabel & 1.249 .728 & 1.396 .204 \\
\hline Total biaya produksi & 1.651 .403 & 1.797 .879 \\
\hline Penerimaan bunga krisan & 4.364 .049 & 4.482 .274 \\
\hline Pendapatan & 2.454 .228 & 2.684 .029 \\
\hline
\end{tabular}

Sumber: Diolah data primer, 2019

Berdasarkan Tabel 5. Diketahui bahwa rata-rata total pendapatan bunga krisan yaitu Rp 2.684.029,- m2/tahun. Menurut penelitian penelitian Utami (3013) pendapatan bunga anggrek yaitu Rp 790.000,- $\mathrm{m} 2$ / tahun. Menurut penelitian Andri et., al (2015) pendapatan bunga mawar yaitu Rp 5.917.503,- $\mathrm{m} 2 /$ tahun. Hal ini dapat disimpulkan bahwa pendapatan paling tinggi terjadi pada bunga krisan.

Tabel 5. Penerimaan dan Pendapatan Bunga Krisan, Anggrek dan Mawar

\begin{tabular}{lrrr}
\hline \multirow{2}{*}{ Keterangan } & \multicolumn{3}{c}{ Pendapatan Usahatani } \\
\cline { 2 - 4 } & \multicolumn{1}{c}{ Krisan } & Anggrek & \multicolumn{1}{c}{ Mawar } \\
\hline \multirow{2}{*}{ Total biaya } & 1.797 .879 & 1.460 .000 & --- Rp/ 3 bulan --- \\
produksi & & & 1.282 .497 \\
Penerimaan & 4.482 .274 & 2.250 .000 & 7.200 .000 \\
pendapatan & 2.684 .029 & 790.000 & 5.917 .503 \\
\hline
\end{tabular}

Sumber: Diolah data primer, 2019

Berdasarkan Tabel 6. Diketahui bahwa rata -rata dari pendapatan usahatani lain pada tahun 2017 yaitu Rp 7.172.333,33,- / tahun dan pada tahun 2018 sebesar Rp 7.914.729,2,- / tahun. Usahatani lain meliputi usahatani selada, bawang daun, seledri dan beternak kambing. Rata - rata pendapatan non usahatani yaitu pada tahun 2017 yaitu Rp 19.800.000,- / tahun meningkat pada tahun 2018 sebesar Rp 21.708.000,- / tahun. Sehingga dapat disimpulkan rata -rata pendapatan usahatani lain dan non usahatani pada tahun 2018 lebih tinggi dibanding tahun 2017.

Tabel 6. Total rata - rata pendapatan selain bunga krisan.

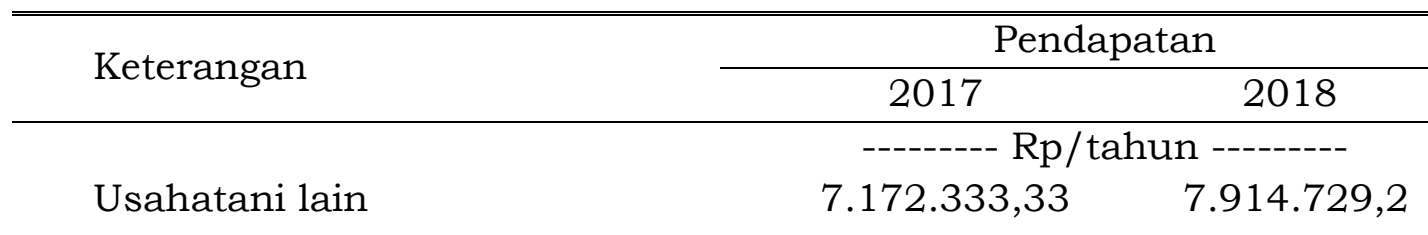


Non usahatani

19.800 .000

21.708 .000

Sumber: Data Primer Penelitian Diolah, 2019.

\section{Pengeluaran Petani Bunga Krisan}

Pengeluaran usahatani bunga krisan meliputi pengeluaran pertanian dan non pertanian, sedangkan pengeluaran non pangan sendiri meliputi pengeluaran pangan dan pengeluaran non pangan.

Tabel 7. Pengeluaran Petani Bunga Krisan

\begin{tabular}{lcr}
\hline \hline \multirow{2}{*}{ keterangan } & \multicolumn{2}{c}{ Pengeluaran } \\
\cline { 2 - 3 } & \multicolumn{1}{c}{2017} & \multicolumn{1}{c}{2018} \\
\hline & $---------\mathrm{Rp} /$ tahun & -------- \\
Total biaya produksi & 62.421 .846 & 66.635 .779 \\
Pengeluaran pangan & 9.448 .386 & 9.920 .268 \\
Pengeluaran non pangan & 9.825 .294 & 10.207 .726 \\
Total pengeluaran RT petani & 19.273 .656 & 20.127 .994 \\
Total pengeluaran Petani & 81.695 .502 & 86.763 .773 \\
\hline
\end{tabular}

Sumber: Diolah data primer, 2019

Berdasarkan Tabel 7. Diketahui bahwa total pengeluaran petani bunga krisan pada tahun 2017 sebesar Rp 81.695.502,- /tahun meningkat pada tahun 2018 sebesar Rp 86.763.773,- /tahun. Total pengeluaran petani diperoleh dari penjumlahan antara total biaya produksi dengan total pengeluaran rumah tangga petani. total pengeluaran rumah tangga petani terdiri dari pengeluaran pangan dan pengeluaran non pangan. Rata - rata total pengeluaran pangan yaitu Rp 9.448.386,/ tahun pada tahun 2017 dan meningkat sebesar Rp 9.920.268,- / tahun pada tahun 2018, sedangkan rata - rata total pengeluaran non pangan pada tahun 2017 yaitu Rp 9.825.294,- / tahun dan meningkat pada tahun 2018 sebesar Rp 10.2017.726,/tahun. Berdasarkan data tersebut diketahui bahwa pengeluaran non pangan lebih tinggi dibanding pengeluaran pangan, artinya kesejahteraan petani tinggi. Hal ini sesuai dengan pendapat Rini (2011) yang menyatakan bahwa alokasi biaya yang dikeluarkan untuk membeli makanan lebih tinggi dibanding dengan non makanan maka hal tersebut menunjukkan bahwa kesejahteraan petani tersebut rendah, begitupun sebaliknya.

\section{Nilai Tukar Petani Bunga Krisan}

Berdasarkan Tabel 8. Diketahui bahwa NTP bunga Krisan pada tahun 2017 yaitu $175 \%$ meningkat menjadi $179 \%$ pada tahun 2018. Artinya NTP bunga krisan sudah dalam kategori sejahtera karena nilai NTP nya lebih dari 100\%. Nirmala et al., (2015) menyatakan bahwa apabila NTP telah mencapai batas $100 \%$ atau lebih maka dapat disimpulkan bahwa petani telah dalam kondisi sejahtera. Tinggi rendahnya NTP dipengaruhi oleh penerimaan petani apabila penerimaan petani tinngi maka daya beli petani terhadap suatu produk juga akan meningkat. Menurut Masyuri (2007) nilai tukar petani berbanding sebanding dengan daya beli petani, apabila nilai tukarpetani meningkat maka daya beli petani terhadap suatu produk juga akan meningkat sehingga dapat disimpilkan bahwa petani relatif sejahtera. 
Tabel 8. Nilai Tukar Petani Bunga Krisan

\begin{tabular}{lll}
\hline \hline \multirow{2}{*}{ Keterangan } & \multicolumn{2}{c}{ Nilai Tukar Petani } \\
\cline { 2 - 3 } & \multicolumn{1}{c}{2017} & \multicolumn{1}{c}{2018} \\
\hline Pengeluaran & \multicolumn{1}{c}{------ Rp/tahun ------ } \\
Total biaya produksi & 1.935 .077 .239 & 2.065 .709 .136 \\
$\quad$ Pengeluaran non pertanian & 597.483 .327 & 623.967 .822 \\
Total pengeluaran & 2.532 .560 .565 & 2.689 .676 .958 \\
Penerimaan & & \\
Pengeluaran bunga krisan & 4.791 .850 .000 & 5.267 .650 .000 \\
Penerimaan usahatani lain & 13.150 .000 & 15.000 .000 \\
Total penerimaan & 4.805 .000 .000 & 5.282 .650 .000 \\
\hline Rata - rata NTP bunga Krisan (\%) & 175 & 179 \\
Rata - rata NTP krisan + Usahatani & 180 & 185 \\
lain (\%) & & \\
\hline Sumber & & \\
\hline
\end{tabular}

Sumber: Diolah data primer, 2019

\section{Analisis Regresi Linier Berganda}

Berdasarkan Tabel 9. Dapat dilihat persamaan regresi linier berganda adalah sebagai berikut:

$$
\mathrm{Y}=204,616+0,026 \mathrm{X} 1-0,004 \mathrm{X} 2+0,001 \mathrm{X} 3-1,405 \mathrm{E} 6 \mathrm{X} 4+0,627 \mathrm{X} 5+\mathrm{e}
$$

Persamaan tersebut dapat dijelaskan sebagai berikut:

Konstanta (a) mempunya nilai 204,616, artinya apabila luas lahan, biaya produksi, penerimaan bunga krisan, pengeluaran rumah tangga petani dan jumlah anggota keluarga bernila nol, maka NTP bunga krisan pada Kelompok Tani Gemah Ripah bernilai 204,616. Koefisien regresi variabel luas lahan (X1) penerimaan bunga krisan (X3) dan jumlah anggota keluarga (X5) bernilai positif berturut - turut yaitu 0,026, 0,001 dan 0,627 artinya apabila variabel luas lahan, penerimaan bunga krisan dan jumlah anggota keluarga mengalami kenaikan sebesar satu nilai maka NTP bunga krisan akan mengalami kenaikan berturut - turut sebesar 0,026, 0,001 dan 0,627 dengan asumsi bahwa variabel lain bernilai tetap. Koefisien regresi variabel biaya produksi (X3) dan pengeluaran rumah tangga bernilai negartif bertut - turut sebesar -0,004 dan -1,405E6, artinya apabila variabel biaya produksi dan pengeluaran rumah tangga mengalami kenaikan sebesar satu nilai maka NTP bunga krisan akan mengalami penurutan berturut - turut sebesar 0,004 dan 1,405E6.

Berdasarkan hasil uji serempak $(F)$ diperoleh hasil bahwa variabel biaya produksi, luas lahan, penerimaan usahatani bunga krisan, pengeluaran rumah tangga dan jumlah anggota keluarga secara serempak berpengaruh nyata terhadap NTP. Berdasarkan hasil uji parsial (t) diperoleh hasil bahwa variabel luas lahan, biaya produksi, penerimaan usahatani bunga krisan, dan pengeluaran rumah tangga secara parsial berpengaruh nyata terhadap NTP, sedangkan jumlah anggota keluarga secara parsial tidak berpengaruh nyata terhadap NTP. 
Berdasarkan hasil uji koefisien determinasi menunjukkan nilai 0,881 artinya variabel $\mathrm{X}$ berpengaruh terhadap variabel $\mathrm{Y}$ sebesar 88,1 \% sedangkan $11,9 \%$ nya di pengaruhi oleh variabel lain.

Tabel 9. Hasil Uji Analisis Regresi Linier Berganda

\begin{tabular}{|c|c|c|c|c|c|}
\hline \multirow{2}{*}{ Variabel } & \multicolumn{2}{|c|}{$\begin{array}{l}\text { Unstandardized } \\
\text { Coefficients }\end{array}$} & \multirow{2}{*}{$\begin{array}{c}\begin{array}{l}\text { Standardized } \\
\text { coefficients }\end{array} \\
\text { Beta }\end{array}$} & \multirow[b]{2}{*}{$\mathrm{t}$} & \multirow[b]{2}{*}{ Sig. } \\
\hline & B & $\begin{array}{l}\text { Std. } \\
\text { Error }\end{array}$ & & & \\
\hline Konstanta & 204,616 & 60,838 & & 3,363 & 0,002 \\
\hline Luas lahan (X1) & 0,026 & 0,004 & 0,775 & 7,253 & 0,000 \\
\hline Biaya produksi (X2) & $-0,004$ & 0,001 & 0,360 & 5,300 & 0,000 \\
\hline Penerimaan (X3) & 0,001 & 0,000 & 0,338 & 5,097 & 0,000 \\
\hline Pengeluaran RT tani (X4) & $-1,405 \mathrm{E} 6$ & 0,000 & $-0,237$ & $\begin{array}{c}- \\
2,175\end{array}$ & 0,039 \\
\hline Jumlah anggota kel. (X5) & 0,627 & 2,615 & 0,018 & 0,240 & 0,812 \\
\hline
\end{tabular}

Sumber: Diolah data primer, 2019

\section{KESIMPULAN DAN SARAN}

\section{Kesimpulan}

Kesimpulan dari penelitian ini adalah:

1. Nilai tukar petani bunga krisan pada tahun 2017 secara signifikan berbeda dengan tahun 2018.

2. Berdasarkan hasil analisis diketahui bahwa variabel luas lahan, biaya produksi, penerimaan bunga krisan dan pengeluaran rumah tangga petani secara signifikan berpengaruh terhadap NTP bunga krisan, sedangkan variabel jumlah anggota keluarga secara signifikan tidak berpengaruh terhadap NTP bunga krisan.

\section{Saran}

Pemerintah sebaiknya turun tangan untuk membantu petani dalam menstabilkan hargapenjualan pada bulan - bulan tertentu yang mengalami penurunan harga ataupun permintaan terhadap bunga krisan, sehingga perbedaan nilai tukar dari tahun ketahun tidak terlalu signifikan dan petani bunga krisan tetap berada diatas angka sejahtera.

\section{DAFTAR PUSTAKA}

Andri, K. B., J. F. Willem, and A. Tumbuan, 2015. Potensi Pengembangan Agribisnis Bunga Anggrek Di Kota Batu Jawa Timur. J. LPPM Bidang EkoSosBudKum.2(1), 19-30.

Arifin, Z., Sriyoto dan E. Yuliarti, 2012.Analisis pendapatan dan nilai tukar petani karet Rakyat di Desa Air Sekamanak Kecamatan Ketahun Kabupaten Bengkulu Utara. J. Pertanian.11(1): 113-124. 
Arikunto, J. 2009. Akuntansi Pajak dengan Microsoft Exel. Jakarta: Elex Media Komputindo.

Badan Pusat Statistik. 2016. Luas Panen $\left(\mathrm{m}^{2}\right)$, Produksi dan Rata-Rata Produksi Tanaman Hias di Kabupaten Semarang Menurut Kecamatan Tahun 2016. Diakses dari https://semarangkab.bps.go.id/pada tanggal 22 Maret 2018.

Dinas Pertanian Kabupaten Semarang. 2017. Keragaan Luas Panen, Produksi dan Produktivitas Krisan di Kabupaten Semarang Tahun 2014 sampai dengan 2017. Dinas Pertanian Kabupaten Semarang. Semarang.

Kasiram, M. 2008. Metode Penelitian Kuantitatif-Kualitatif. Malang: UIN Malang Press.

Masyhuri, 2007. Revitalisasi Pertanian Untuk Mensejahterakan Petani. Makalah pada Konpernas XV dan Kongres XIV PERHEPI, Surakarta, 3-5 Agustus 2007.

Mubyarto, 1995. Pengantar Ekonomi Pertanian.Jakarta: PT. Pustaka LP3S.

Rini, S. T. 2011. Analisis ketahanan pangan rumah tangga petani lahan kering di Kabupaten Boyolali. Skripsi. Surakarta. Universitas Sebelas Maret,

Nirmala, A. R., N. Hanani dan A. W. Muhaimin. 2017. Analisis Faktor Faktor yang Mempengaruhi Nilai Tukar Petani Tanaman Pangan di Kabupaten Jombang. J.Habitat.27(2): 66-71.

Santi, Y.M., 2009. Analisis usaha agroindustri keripik belut sawah (Monopterus Albus Zuieuw) di Kabupaten Klaten.Disertasi. Surakarta. Universitas Sebelas Maret.

Santoso, S. 2010. StatistikaParametrik, Konsep dan Aplikasi dengan SPSS. Jakarta: Gramedia.

Sartika, C., M.Y. Balaka, and W.A. Rumbia. 2016. Studi faktor-faktor penyebab kemiskinan masyarakat Desa Lohia Kecamatan Lohia Kabupaten Muna. J. Ekonomi Uho, 1(1) 16-17.

Sarwono, S. 1992. Psikologi Lingkungan.Jakarta: Gramedia,

Sugiarto. 2008. Analisis tingkat kesejahteraan petani menurut pola pendapatan dan pengeluaran di perdesaan. Seminar Nasional Dinamika Pembangunan Pertanian dan Perdesaan: Tantangan dan Peluang Bagi Peningkatan Kesejahteraan Petani. Bogor, 19 November 2008.

Sugiyono. 2016. Metode Penelitian Kuantitatif, Kualitatif, dan R\&D. Cetakan ke-23. Bandung: Alfabeta.

Suratiyah, K., 2015. Ilmu Usaha tani (edisi revisi). Jakarta: Penebar Swadaya Grup.

Swasti K., Karno dan T., Ekowati . 2014. Strategi pengembangan agribisnis bunga krisan di kecamatan bandungan kabupaten semarang. Agromedia, 32(2) : 1718. 